\title{
The Study on Ken Hyland's Interactional Model in OUP Publications
}

\author{
Mohammad Akbarpour ${ }^{1}$, Hossein Sadeghoghli ${ }^{2}$ \\ ${ }^{1}$ Department of English Teaching, East Azerbaijan Science and Research Branch, Islamic Azad University, Tabriz, Iran \\ ${ }^{2}$ Department of English Studies, East Azerbaijan Science and Research Branch, Islamic Azad University, Tabriz, Iran
}

Email address:

akbarpour100@gmail.com (M. Akbarpour), hsadeg2000@yahoo.com (H. Sadeghoghli)

\section{To cite this article:}

Mohammad Akbarpour, Hossein Sadeghoghli. The Study on Ken Hyland's Interactional Model in OUP Publications. International Journal of Language and Linguistics. Vol. 3, No. 4, 2015, pp. 266-270. doi: 10.11648/j.ij11.20150304.21

\begin{abstract}
This study is an attempt to understand how different authors of research articles in diverse fields draw on interactional devices in their writings to convince and interact with their audience. In order to do so seventy research articles from Economics, Humanities, Life Sciences, Social Sciences, Law, Mathematics \& Physical Sciences, and Medicine were selected to constitute the data of this study. Then Ken Hyland's interactional model was applied to find out to what extent writers used interpersonal resources in their writings. The results showed some considerable similarities and variations cross and across the fields. The findings of this study may also provide some useful insights into the teaching of writing research articles and may be helpful for writing teachers and students.
\end{abstract}

Keywords: Metadiscourse, Interactional Model, Interactive Model, Research Genre

\section{Introduction}

It is generally acknowledged that interpersonally writing enable authors to communicate, engage, and interact with their readers continuously in a persuading way. Hyland has dedicated his attempts to theorize this way of looking at written or spoken language and proposed a comprehensive model. His metadiscoursal thinking embodies the idea that writing or speaking is not just mere and faceless transition of information and knowledge, but communication takes place with regard to social practices in that community. Hyland (2005.p. 37) defines metadiscourse as "the cover term for the self-reflective expressions used to negotiate interpersonal meanings in a text, assisting the writer(speaker) to express a viewpoint and engage with readers as members of a particular community." In other words they are resources used by writers to fulfill their organizational objectives, engage their readers, and voice their viewpoint to both their content and readers.

Hyland's suggested metadiscourse model includes interactive and interactional metadiscourse. He defines (2005.p. 49) the interactive dimension as "this concern the writer's awareness of a participating audience and the ways he or she seeks to accommodate its probable knowledge, interests, rhetorical expectations, and processing needs." The interactive resources enable writers to organize their texts in a way that guides their readers to accept preferred interpretations. It can be concluded that the interactive model embodies organizational attempts of writers to direct their readers towards their intended interpretation. But Hyland defines (2005. P. 49)the interactional dimension as "this concerns the ways writers conduct interaction by intruding and commenting on message. The writer's goal here is to make his or her view explicit and to involve readers by allowing them to respond to the unfolding text. This is the writer's expression of a textual 'voice', or communityrecognized personality, and includes the way he or she conveys judgments and overtly align him- or herself with readers." The interactional part, that is the base of this research, is concerned with writer's attempt to express opinions and engage readers in a way that it requires writers to take into consideration their reader's potential reactions and respond to them and to sum up; it deals with personal information. It is also worth noting that interactional metadiscourse includes the following categories;

Hedges: Hedging is a strategy used by writers or speaker to avoid full commitment to proposition. Therefore it can be said that hedges refer to elements such as may, perhaps... in 
a text that reveal writers or speakers uncertain stance and position.

Boosters: Boosting includes resorting to some features that show writers' certain positioning. Absolutely, certainly... are some expressions used by language users to reveal their full commitment to proposition.

Self mentions: Self mentions, as its names suggests, refer to those elements in a text that writers use to refer to themselves. I, we ... represent this category.

Attitude markers: Attitude markers are those elements such as surprisingly, unfortunately...that writers use to express their opinion to proposition.

Engagement markers: this strategy shows writers' tendency to make their readers participate in the text. Therefore they entails those features that writers use to refer to readers.

Since the suggestion of metadiscourse and its model, it has attracted the attention of different researchers in different areas to carry out studies in this respect. Metadiscoursal researchers study different genres from different perspectives In research genre, Khajavy and Vahidnia in 2013 conducted a research to study metadiscourse in applied linguistics and engineering disciplines. In general their results showed that engineering writers used interpersonal metadiscourse more than applied linguistics authors. Engineering writers drew on hedging more than applied linguistics ones. Applied linguistics tended to use boosters and attitude markers more than engineering. And in the use of engagement markers and self mentions there were not such a significant difference.

Abdi (2011) carried out a research to study different subsections of articles in terms of the distribution of Hyland's metadiscourse markers in social and natural sciences. On the whole, the analysis of this study showed that there were very small differences in the natural sciences and social sciences concerning the distribution of interactional metadiscourse. On the whole, the cases of interactional markers turn out to emphasize some significant differences. Putting aside boosters that were highly employed by both sciences, other interactional markers including hedges, attitude markers, engagement markers, and self mentions were utilized by the social science writers more than the natural science writers. In other words, interpersonally composing research articles were more attended by the social science writers than the natural science ones.

These studies have concentrated on the subsections of research and have limited their studies to two fields or disciplines. Therefore this study is an attempt to provide a general picture concerning the distribution of interactional devices. The hope is that the findings of this study could help research article authors about how to draw on interactional resources.

\section{Methodology}

\subsection{Material}

The data of this investigation came from 70 articles randomly selected from seven fields including Social Sciences, Medicine, Humanities, Life Sciences, Economics, Law, Mathematics \& Physical Sciences (M\&PSs) from the Oxford Journals. The logic behind selecting Oxford as the focus of this study is that it is not only a well known and prestigious source of textbooks across the world, it is also one of the leading journals in the world that publishes various and important research articles and it is taken for granted that great works are published in this journal.

The corpus of this study coming from these fields totaled 541490 words. Economics research articles with 108397 words, Humanities with 68122 words, Law with 109512 words, Life Sciences with 55703 words, M\&PSs with 87769 words, Medicine with 53074 words, and finally Social Sciences with 58913 words comprised the corpus of this. Among these articles, research articles from Law used more words and the least occurrences belonged to the medical articles. Table 1 shows word counts clearly;

\subsection{Data Collection Procedure}

The corpus of this investigation came from Oxford Journal. Seventy articles were selected from seven fields. Two journals were selected from each field to represent that field. American Journal of Agricultural Economics and Journal of Economic Geography represented Economics. From each of these journals five articles were selected. Applied linguistics and ELT Journals were culled from Humanities. For Law, International Journal of Law and Information Technology and International Journal of Law, Policy and the Family were chosen. Microscopy and Protein Engineering, Design \& Selection were opted for Life Sciences. From Mathematics and Physical Sciences, IMA Journal of Mathematical Control and Information and The Computer Journal were picked. Health Education and International Health Journals were the representative of Medicine. And finally research articles from The Computer Journal and The Computer Journal were culled to comprise the corpus of this study.

\subsection{Data Analysis}

The analysis of metadiscourse was carried out by using Hyland's identified list of words in his book, but also other potential options discovered by various researchers were added to this list because Hyland has confirmed that it is an open category that allows researchers to contribute to the identification of metadiscoursal items. Another important point is that metadiscourse analysis is functional analysis. In other words, Hyland (2005:35) has proposed that metadiscourse is a relative concept meaning text items only function as metadiscourse in relation to another part of the text and instead of regarding it as a strictly linguistic phenomenon it is considered as rhetorical and pragmatic. The important consideration in the analysis of metadiscourse is the necessity of approaching it manually in the process of assigning items to the role of functioning as metadiscourse in relation to its context. 
Table 1. Word Frequencies in the Fields.

\begin{tabular}{llllllll}
\hline & Economics & Humanities & Law & Life Sciences & M\&P Sciences & Medicine & Social Sciences \\
\hline Words & 108397 & 68122 & 109512 & 55703 & 87769 & 53074 & 58913 \\
Total Words & 541490 & & & & & & \\
\hline
\end{tabular}

\section{Results}

Outcomming results of this study organized in the following ways: at first, our concentration is hugely on understanding the overall interactional metadiscourse frequencies across the fields in general without focusing on each individual category. Secondly, the attempt is to find out the distribution of each interactional category across and cross fields individually.

\subsection{Overall Interactional Metadiscourse Frequencies}

The findings of this study show that authors in Economics used interactional resources more than the other fields. Figure 1 shows the frequency of interactional categories as 25.3 per 1000 words which is more than other fields. Interestingly as the figure shows Mathematics and Physical Sciences with the frequency of 22.4 per 1000 words used interactional metadiscourse more than other fields after Economics and, as it was expected, in Humanities, the occurrence of 21 per 1000 words, interactional items were used more than fields such as Social Sciences(19.2 per 1000 words), Law (15.1 per 1000 words), Medicine (13.5 per 1000 words), and Health sciences (10.6 per 1000 words). In other words, in general, it can be said that the soft sciences such as humanities, law,... used the interactional devices more than the hard ones such as medicine,...
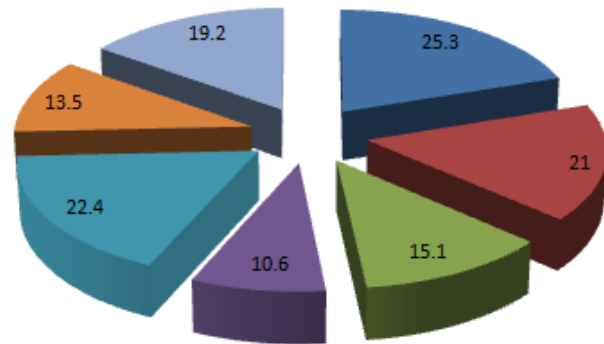

- economics

numanities

Iaw

- health sciences

- M\&P sciences

- medicine

In soicia sciences

Figure 1. Overall Interactional Metadiscourse Frequencies in Divers Scientific Fields (per 1000 words).

\subsection{Distribution of Interactional Metadiscourse Across All Fields}

Almost in all fields, hedges were the most frequently used interactional items in research articles. Economics, Humanities, Social Sciences, and Law with 10.4, 9.2, 7.8, and 7.7 per 1000 words respectively relied on hedges to present propositional content. Noticeably Medicine also tended to be cautious about presenting its positioning. The findings show that all these fields, except M\&P Sciences, used hedging at least two or three times more than other categories. Even the same realization appeared in Medicine and Health Sciences that are considered to belong to hard sciences. Consequently it can be concluded that hedges occurred frequently more than other devices in the fields.

The results concerning the distribution of boosters revealed almost a homogeneous use in the fields but Humanities' research articles were drawn on certainty devices partially more than the rest of fields. Therefore it can be realized that there was not such a significant difference in the use of boosters across these fields.

Self mentioning items that allow writers to establish appropriate relations between the partners of communication, occurred in some fields more than the other ones. M\&P Sciences with 7.9 per 1000 words, Economics with 5.6 per 1000 words and Social Sciences with 4.2 per 1000 words significantly used self mentioning more than Humanities, Law, Medicine, and Health Sciences. Law is at the bottom of these fields concerning the distribution of self mentions by the 1.2 occurrence per 1000 words.

Engagement markers, referring to those elements in the text that enable writers to engage their audience, were not used more by research article writers in contrast to other categories such as hedges and boosters. There was not found such a significant variation in the distribution of engagement markers in the fields except M\&P Sciences. In this field among other fields engagement devices occurred 7.1 per 1000 words, showing a strong tendency in M\&P Sciences to include their audience into the text to direct them towards their intended interpretation.

Attitude markers in contrast to hedges, boosters, self mention engagement markers were the less frequently occurring items in this study. This investigation revealed that all research article authors regardless of field consideration tended to avoid using attitude markers. Therefore there was not found any considerable difference in the use of this category.

Finally at the end of this section, it is worth noting that the distribution of interactional categories from the most frequent used categories to the less used ones showed this hierarchy: hedges, self mentions, boosters, engagement markers, and attitude markers. Therefore it can be said that they paid assiduous attention to precluding their attitudinal terms from their writing as much as possible. 
Table 2. Overall Frequencies of Interactional Metadiscourse (per 1000 words).

\begin{tabular}{|c|c|c|c|c|c|c|c|c|}
\hline & Economics & M\&P Sciences & Humanities & Social Sciences & Law & Medicine & Health Sciences & Mean \\
\hline Attitude Markers & 2.2 & 0.7 & 2.3 & 1.4 & 1.4 & 1.4 & 0.8 & 1.45 \\
\hline Boosters & 3.5 & 3.3 & 4.8 & 3.7 & 2.7 & 2.2 & 2 & 3.17 \\
\hline Self Mentions & 5.6 & 7.9 & 2.2 & 4.2 & 1.2 & 2.1 & 2.2 & 3.2 \\
\hline Engagement Markers & 3.3 & 7.1 & 2.3 & 1.9 & 1.9 & 1.5 & 1.5 & 2.78 \\
\hline Hedges & 10.4 & 3.2 & 9.2 & 7.8 & 7.7 & 6.2 & 4 & 6.9 \\
\hline Total & 25.3 & 22.4 & 21 & 19.2 & 15.1 & 13.5 & 10.6 & \\
\hline
\end{tabular}

\section{Discussion}

In the result section, the distribution of interactional markers in each field corroborated that the fields such as Economics, Mathematics \& Physical Sciences, Humanities, and Social Sciences drew on interactional metadiscourse more than the fields such as Medicine, and Health Sciences. In other words those fields that fall in the category of soft sciences (Economics, Law, Social Sciences, and Humanities in this study) tended to exploit interactional devices more than those of hard sciences (Health Sciences, Medicine, and Mathematics \& Physical Sciences in this study). This finding is almost in line with the previous studies conducted by Hyland 2005, Khedri, and Abdi 2011. This realization is completely consistent with Hyland's claim that soft sciences draw on interactional elements in their writings more than hard sciences due to their interpretative nature and verifies writers' argumentative efforts to convince their readers. It means that hard knowledge domains make efforts to rely on their scientific methods and consequently authors of these domains deemphasize their presence if possible, but on the other hand, soft science domains need employing interactional devices mostly to get their reader to understand their intended interpretation.

Among the soft sciences in this study the highest and lowest frequencies belonged to Economics and Law respectively. Economics, Humanities, and Social Sciences used interactional devices considerably more than Law and this lowest occurrence may be due to their writers' tendency to avoid positioning in their texts in order to outline law and legal principles and procedures. But among the hard knowledge fields in this study M \& P Sciences (22.4 per 1000 words) utilized interactional features more than Medicine and Health Sciences (13.5 and 10.6 per 1000 words respectively). This finding may signify the increasing dependence of hard science writers on interactional resources to have their claims accepted on the basis of their community norms and expectations.

Hedges were the most frequently occurring categories almost in the whole fields in this investigation. If we assign these fields to the dichotomy of soft and hard sciences, we will realize that those fields that fall in the soft science category such as Economics, Social Sciences, Law, and Humanities (the mean=8.82 per 1000 words) drew on hedges around two times more than those of the hard sciences including M \& P Sciences, Medicine, and Health Sciences (the mean=4.46). This study does not provide support for
Abdi's study in 2011 that showed boosters were used more than hedges by both soft and high sciences in that study. Expectedly this heavy reliance of hedging in research articles, particularly in Economics, Social Sciences, Humanities and Law reveals the interpretative nature of soft sciences over and over again in that they argue their claims in a cautious way. It is also understandable from this study that hedging plays an integral role in communicating proposition in hard science domains that shows writers 'deference to readers to get involved in communicating and bringing other alternative voices.

Findings of this study concerning the distribution of interactional categories revealed that self mentions and boosters were the next frequently used devices across the fields ( the mean occurrences of 3.6 and 3.1 per 1000 words). An interesting point is that there was not any considerable variation concerning the use of boosters in the soft and hard fields. In other words, the soft fields used booster partially more than the hard fields but inside the hard and soft sciences, authors resorted to boosting strategy quite equally. This finding is almost in line with the previous studies such as Khajavy and Vahidnia in 2013 that showed that boosters are one of the frequently occurring devices in writing research articles. Expectedly maybe this partially more use of boosters by soft sciences reflects that soft knowledge domains' need to draw on these devices to persuade their audience. Interestingly, findings of the study revealed that self mentions were used frequently in all the fields after hedging or in the hard and soft sciences. This is not in line with the previous studies such as Khajavy and Vahidnia in 2013 that showed a fainted willingness of research articles in the use of self mentions. This increasing appearance of self mentions in soft and especially hard sciences may be showing a changing attitude of authors to represent themselves in their texts.

Finding of the study about the distribution of engagement markers shows, as expected, that the hard fields partially used engagement markers more than the soft fields. This finding is consistent with other studies in this regard. This is maybe due to the fact that writers in hard knowledge domains like their readers to go through and replicate procedures exactly in the same way identified by them.

Attitude markers were considerably the less frequently used category in the fields in this study and did not show such a variation across the fields $(\mathrm{SD}=.6)$. This finding is not in line with the previous studies, such as Khajavy and Vahidnia in 2013, that showed that attitude markers were one of the most frequently used strategies after hedges. This decreasing willingness may display writers' growing 
tendency to avoid expressing their feelings towards proposition.

\section{Conclusion}

This study was carried out with the aim of pinning down the ways writers of diverse fields communicate and interact with their readers and consequently revealing the ongoing norms and conventions of communication in their discourse community. The findings provide some useful insights into our realization that authors of research articles tend to draw on interactional resources in accordance with their discourse communities that reflects their cultural and social preferences in writing. Of course, findings of this study confirm that certainty and uncertainty markers hold significant roles in authoring research artices as it was shown by some previous studies. Interestingly, the increasing appearance of self mentions in this study alludes to the changing tendency of authors to present themselves in their writings. Therefore it can be concluded that writer-reader interactions in a text is an integral part of achieving communicative purposes in every discourse community.

\section{References}

[1] Abdi. R. (2011). Metadiscourse strategies in research articles: A study of the differences across subsections. The Journal of Teaching Language Skills (JTLS), 3(1), 1-16.

[2] Adel, A. (2006). Metadiscourse in L1 and L2 English. Philadelphia: John Benjamins.

[3] Amiryousefi, M. \& Eslami Rasekh, A. (2010). Metadiscourse: Definitions, issues and its implications for English. English Language Teaching, 3(4), 159-167.

[4] Bahtia, V. K. (1997). Introduction: genre analysis and world Englishes. World Englishes. 16(3), 313-319.

[5] Davies, A., \& Elder, C. (Eds.). (2004). The handbook of applied linguistics. Oxford, UK: Blackwell.

[6] EBRAHIMI, S.J. \& HENG, C. S. \& Khedri, M. (....).Interactional metadiscourse markers in academic research article result and discussion sections. The Southeast Asian Journal of English Language Studies , 19 (1), 65 - 74 .

[7] Firoozian Pooresfahani, A. \& Khajavy , G.H. (2012). A contrastive study of metadiscourse elements in research articles written by Iranian applied linguistics and engineering writers in English. English Linguistics Research, 1(1), 88-96.

[8] Gillaerts, P. \& Van de Velde, F. (2010). Interactional metadiscourse in research article abstracts. Journal of English for Academic Purposes ,9 , 128-139.

[9] Hyland, K. (1994). Hedging in academic writing and EAP textbooks. English for Specific Purposes, 13, 239-256.

[10] Hyland, K. (1996). Talking to the academy: Forms of hedging in science research articles Written Communication13 (2),
$251-281$

[11] Hyland, K. (1998). Persuasion and context: the pragmatics of academic metadiscourse. Journal of Pragmatics, 30, 437-455.

[12] Hyland, K. (1999). Talking to students: Metadiscourse in introductory textbooks. English for Specific Purposes, 18(1), $3-26$.

[13] Hyland, K. (2000).Disciplinary discourses: Social interactions in academic writing. London: Longman.

[14] Hyland, K. (2001). Bringing in the reader: Addressee features in academic writing. Written Communication, 18(4), 549-574.

[15] Hyland, K. (2002a). Directives: Argument and engagement in academic writing. Applied Linguistics, 23(2), 215-239.

[16] Hyland, K. (2002b) Authority and invisibility: Authorial identity in academic writing .Journal of Pragmatics, 34(8), 1091-1112.

[17] Hyland, K. (2002c). Options of identity in academic writing. ELT Journal56 (4), 351-358.

[18] Hyland, K., \& Tse , P. (2004a). Metadiscourse in academic writing: a reappraisal. Applied Linguistics, 25(2), 156-177.

[19] Hyland, K. (2004b). Disciplinary interactions: metadiscourse in L2 postgraduate writing. Journal of Second Language Writing, 13, 133-151.

[20] Hyland, K. (2004c) Disciplinary Discourses: social interactions in academic writing. Michigan:University of Michigan Press

[21] Hyland, K. (2005a). Metadiscourse. London: Continuum.

[22] Hyland, K. (2005b).Metadiscourse: Exploring writing in interaction. London: Continuum.

[23] Hyland, K. (2005c). Stance and engagement: a model of interaction in academic discourse. Discourse Studies, 7(2), 173-192.

[24] Hyland, K. (2005d). Representing readers in writing: Student and expert practices. Linguistics and Education 16,363-377.

[25] Hyland, K. (2008). Persuasion, interaction, and the construction of knowledge: Representing self and others in research writing. Interactional Journal of English Studies, 8(2), $1-23$.

[26] Swales, J. (1990).Genre analysis: English in academic and research settings. Cambridge: Cambridge University Press.

[27] Khabbazi-Oskouei, L. (2013). Propositional or nonpropositional, that is the question: A new approach to analyzing'interpersonal metadiscourse' in editorials. Journal of Pragmatics, 47 ,93-107.

[28] Kuhi, D., \& Behnam, B. (2010). Generic variations and metadiscourse use in the writing of applied linguists: A comparative study and preliminary framework. Written Communication, 28 (1), 97-141.

[29] Thompson, G. (2001). Interaction in academic writing: Learning to argue with the readers. Applied Linguistics, 22(1), 58-78. 